\title{
Analysis of the Alkane Hydroxylase Gene and Long-Chain Cyclic Alkane Degradation in Rhodococcus
}

\author{
Taiki Kawagoe, Kenzo Kubota, Kiwako S. Araki, Motoki Kubo \\ Department of Biotechnology, Faculty of Life Sciences, Ritsumeikan University, Shiga, Japan \\ Email: kubo@sk.ritsumei.ac.jp
}

How to cite this paper: Kawagoe, T., Kubota, K., Araki, K.S. and Kubo, M. (2019) Analysis of the Alkane Hydroxylase Gene and Long-Chain Cyclic Alkane Degradation in Rhodococcus. Advances in Microbiology, 9, 151-163.

https://doi.org/10.4236/aim.2019.93012

Received: January 30, 2019

Accepted: March 2, 2019

Published: March 5, 2019

Copyright $\odot 2019$ by author(s) and Scientific Research Publishing Inc. This work is licensed under the Creative Commons Attribution International License (CC BY 4.0).

http://creativecommons.org/licenses/by/4.0/

\begin{abstract}
To characterize the long-chain cyclic alkane ( $c$-alkane) degradation of bacteria in Rhodococcus, we analyzed the relationship between the alkane hydroxylase gene $(a l k B)$ and long-chain $c$-alkane degradation in 19 species. Eleven strains which were isolated from nature using long-chain $c$-alkane as a substrate were identified as $R$. erythropolis, and all were shown to carry the alkB [alkB $\mathrm{R} 2$ type]. This gene type was also carried by two other species, $R$. rhodochrous and $R$. baikonurensis. In total, 17 species of the genus Rhodococcus carried alkB, but the gene types differed from each other. The two species $R$. rhodnii and $R$. coprophilus did not carry alkB, and their long-chain $c$-alkane degradation levels were low.
\end{abstract}

\section{Keywords}

Alkane Hydroxylase, alkB, Bioremediation, Long-Chain c-Alkane, Rhodococcus

\section{Introduction}

In recent years, environmental pollution by petroleum hydrocarbons has been a serious problem worldwide. To clean up hydrocarbon-contaminated sites, a range of treatments can be performed, including incineration, chemical oxidation (Fenton reaction), washing, and evaporation. However, a lot of energy is required for these treatments [1] [2] [3] [4]. Biological treatments such as bioremediation have been investigated as an effective system of hydrocarbon degradation [5] [6] [7] [8] [9], and many microorganisms with the ability to degrade petroleum hydrocarbons have been isolated from their natural habitat and characterized [10] [11] [12] [13] [14]. However, it is difficult for bacteria to degrade long-chain hydrocarbons, especially long-chain cyclic alkanes (c-alkanes) [15] [16]. Therefore, 
the isolation of bacteria capable of degrading long-chain hydrocarbons is important for the bioremediation of hydrocarbons [17] [18] [19].

Kubota et al. previously isolated hydrocarbon-degrading bacteria (HDB) from their natural habitats, and determined their phylogenetic relationships based on partial sequences of the 16S rRNA gene [20]. This identified many isolated species as belonging to the genera Pseudomonas, Rhodococcus, Gordonia, and Acinetobacter [20]. The strains belonging to the genera Rhodococcus and Gordonia degraded not only long-chain normal alkanes (n-alkanes) but also $c$-alkanes as the sole carbon and energy source [20] [21] [22] [23]. This indicated that the strains degrading long-chain $c$-alkanes have potential for cleaning petroleum hydrocarbon pollutants, because long-chain $n$-alkanes and $c$-alkanes remain in the soil for long periods.

The first step of degrading long-chain $c$-alkanes, the oxidation of hydrocarbons, is catalyzed by alkane hydroxylases (Alk) [24] [25]. For many HDB, alkB genes encoding Alk have been well analyzed [26] [27] [28] [29]. alkB genes are categorized as seven types (alkB1 to alkB7) [30] [31], and many strains of the genus Rhodococcus are known to carry alkB2. However, the relationship between different types of alk genes and the $c$-alkane degradation ability has not been characterized for each species. Moreover, alkB varies among species of the genus Rhodococcus, and oxidizable substrates differ depending on the alkB gene type [32]. For example, Fukuhara et al. [33] revealed that the $R$. erythropolis strain NDKK6, carrying the alkB R2 type, showed a high $c$-alkane degradation ability. Furthermore, the carbon number of the alkyl side chain seemed to influence $c$-alkane degradation [34] [35] [36] [37]. A previous study isolated 11 strains of HDB from the genus Rhodococcus [20], but they have not been characterized yet.

In the present study, we investigated the relationship between alk $B$ genes and long-chain $c$-alkane degradation for 11 isolated strains of Rhodococcus and 19 strains obtained from the NITE Biological Resource Center (NBRC), Japan.

\section{Materials and Methods}

\subsection{Bacterial Strains}

Thirty bacterial strains were used as long-chain $c$-alkane-degrading bacteria. Eleven strains ( $R$. erythropolis NDKK1, $R$. erythropolis NDKK2, $R$. erythropolis NDKK5, R. erythropolis NDKK6, R. erythropolis NDKK7, $R$. erythropolis NDKK48, $R$. erythropolis ODNM1C, $R$. erythropolis NDKY82A, $R$. erythropolis ODMI54, $R$. erythropolis ODNM2B, and $R$. erythropolis NDMI144) were isolated in our previous study [20], and 19 species ( $R$. erythropolis NBRC15567, $R$. rhodochrous NBRC15564, $R$. baikonurensis NBRC100611, $R$. wratislaviensis NBRC100605, $R$. opacus NBRC100624, $R$. ruber NBRC15591, $R$. equi NBRC101255, $R$. percoletus NBRC100626, $R$. jostii NBRC16295, $R$. triatomae NBRC103116, $R$. koreensis NBRC100607, $R$. corynebacterioides NBRC14404, $R$. zopfii NBRC100606, $R$. tukisamuensis NBRC100609, R. maanshanensis NBRC100610, R. pyridinivorans 
NBRC100608, $R$. kroppenstedtii NBRC103113, $R$. rhodnii NBRC100604, and $R$. coprophilus NBRC100603) were obtained from the NBRC.

\subsection{Identification of Bacterial Strains}

The 11 strains from our earlier study were identified based on the full length $16 \mathrm{~S}$ rRNA gene sequence. These strains were cultivated in Luria-Bertani (LB) medium ( $1 \%$ peptone, $0.5 \%$ yeast extract, and $0.5 \% \mathrm{NaCl})$ at $30^{\circ} \mathrm{C}$ with shaking at $200 \mathrm{rpm}$ [36]. Total DNA was extracted from the culture, and the 16S rRNA gene sequence was determined [38] [39]. Sequence data were deposited in the DNA Data Bank of Japan (DDBJ) database

(https://www.ddbj.nig.ac.jp/index-e.html) under accession numbers LC107434 to LC107444. The sequences were also compared with data in the GenBank database using BLAST+2.2.31 which is available at

https://www.ncbi.nlm.nih.gov/blast/. Phylogenetic analyses were carried out for the 11 strains and the additional 19 species whose sequence data were obtained from the GenBank database using ClustalW (version 2.1). The phylogenetic tree was constructed by the neighbor-joining method and bootstrap values were calculated by 1000 replications.

\subsection{Sequences of $a l k B$ and $a l k B$ [alkB R2 Type] Genes}

Sequences of alk $B$ were also determined for 30 strains. PCR was conducted using primers alkB-F (5'-AACTAYMTCGARCAYTAYGG-3')/alkB-R (5'-TGRTCKSTCGYTGVARGTG-3') and alkB R2-F (5'-CGGTTGTGTCGCAGGA-TC-3)/ aIkB R2-R (5'-AACGACTGCGCCAGAGTGAT-3') [31] to confirm the presence of alk $B$ and alkB genes [alkB $\mathrm{R} 2$ type], respectively. alkB and alkB gene [alkB $\mathrm{R} 2$ type] PCR products were $140 \mathrm{bp}$ and $100 \mathrm{bp}$, respectively. alkB primers were designed for the consensus region of HDB. alkB sequences were determined by the ABI PRISM 3100 Genetic Analyzer (Applied Biosystems, Foster City, CA, USA), and sequence data were deposited in the DDBJ database under accession numbers LC107445 to LC107470. Phylogenetic analysis was performed for alkB sequences as described above.

\subsection{Analysis of c-Alkane Degradation by Rhodococcus Strains}

To evaluate bacterial long-chain $c$-alkane degrading abilities, 30 strains were cultivated in modified SW medium with undecylcyclohexane (UDC), dodecylcyclohexane (DDC), and tridecylcyclohexane (TDC) substrates. Pre-culture of each strain was prepared in LB medium. Substrate hydrocarbon $(0.10 \mathrm{~g})$ and pre-culture $(1 \mathrm{ml})$ were inoculated in $100 \mathrm{ml}$ of modified SW medium $(1 \% \mathrm{v} / \mathrm{w}$; per liter: $1.21 \mathrm{~g} \mathrm{NH}_{4} \mathrm{NO}_{3}, 14.3 \mathrm{~g} \mathrm{Na}_{2} \mathrm{HPO}_{4} \cdot 12 \mathrm{H}_{2} \mathrm{O}, 5.44 \mathrm{~g} \mathrm{KH}_{2} \mathrm{PO}_{4}, 0.5 \mathrm{~g} \mathrm{NaCl}, 0.247 \mathrm{~g}$ $\mathrm{MgSO}_{4}, 2.78 \mathrm{mg} \mathrm{FeSO}{ }_{4} \cdot 7 \mathrm{H}_{2} \mathrm{O}, 14.7 \mathrm{mg} \mathrm{CaCl} \cdot 2 \mathrm{H}_{2} \mathrm{O}, 2.01 \mathrm{mg} \mathrm{ZnSO} \cdot \cdot 7 \mathrm{H}_{2} \mathrm{O}, 0.15$ $\mathrm{mg}\left[\mathrm{NH}_{4}\right]_{6} \mathrm{Mo}_{7} \mathrm{O}_{24} \cdot 4 \mathrm{H}_{2} \mathrm{O}, 2 \mathrm{mg} \mathrm{CuSO}_{4} \cdot 5 \mathrm{H}_{2} \mathrm{O}, 0.4 \mathrm{mg} \mathrm{CoCl} \cdot 6 \mathrm{H}_{2} \mathrm{O}, 1.49 \mathrm{mg}$ $\mathrm{MnSO}_{4} \cdot 5 \mathrm{H}_{2} \mathrm{O}, 0.5 \mathrm{~g}$ polypeptone, and $0.25 \mathrm{~g}$ yeast extract) in a baffle flask before incubating at $30^{\circ} \mathrm{C}$ with shaking at $120 \mathrm{rpm}$. 
After 3 days of cultivation, $30 \mathrm{ml}$ of chloroform-methanol (3:1) mixture was added to $100 \mathrm{ml}$ medium and mixed well before centrifuging at $4000 \times \mathrm{g}$ for $30 \mathrm{~min}$. The separated organic layer was taken for gas-chromatographic analysis using a flame ionized detector (GC-FID) (GC-2010, Shimadzu, Kyoto, Japan). The degradation test was carried out in triplicate. The degradation ratio was calculated from the rate of decrease of the peak area of the gas-chromatogram as follows:

1 - (Peak area after cultivation/Peak area before cultivation $) \times 100(\%)$

The concentration of hydrocarbon in the soil was measured using the OCMA-355 oil content analyzer (Horiba, Kyoto, Japan).

\section{Results and Discussion}

\subsection{Identification of Long Chain $c$-Alkane-Degrading Bacteria and Analysis of Alkane Hydroxylase Genes in Rhodococcus}

To identify Rhodococcus strains isolated in our previous study [20], we determined the 16S rRNA gene sequences (1429 - $1472 \mathrm{bp}$ ). Phylogenetic analysis showed that all strains belonged to $R$. erythropolis, based on similarity with the reference strain $R$. erythropolis MPU33 (DNA databank accession number: AB334770) (Figure 1). These strains were isolated from a culture medium containing long chain $c$-alkane as the sole carbon source [20], indicating that the strains carried alkB.

The presence and type of alkB genes in the strains were next examined. All strains carried alkB genes, with 13 Rhodococcus species of the 29 strains used in this study shown to carry alkB (Table 1 and Table 2). alkB sequences of $R$. erythropolis isolated from nature were $98.1 \%-100 \%$ homologous with the alkB R2 type of $R$. erythropolis NDKK6 that has high $c$-alkane degradation ability (Table $1)$. The alkB sequence from $R$. erythropolis NBRC15567 also showed high similarity with alkB $\mathrm{R} 2$ type (95.7\%). Additionally, two other strains ( $R$. rhodochrous and $R$. baikonurensis) obtained from NBRC carried alkB genes with approximately $100 \%$ homology to alkB R2 type (Table 2).

Ten strains also carried alkB genes, but homology analysis showed that their sequences differed from alkB R2 type ( $21.9 \%$ to $78.3 \%$ homologous) so original alk $B$ names were given to each alkB gene type (Table 2). The similarity of $R$. opacus and $R$. percolatus alkB genes was $99.7 \%$ (Figure 2), so they were named alk $B$ ROP type. The remaining 6 species lacked alk $B$ genes. Phylogenetic analysis based on alkB revealed separate clusters of alkB [alkB R2 type] and alkB [non-alkB R2 type] groups (Figure 2). In the Rhodococcus genus, 3 groups were categorized as follows: first group included species such as $R$. baikonurensis and $R$. rhodochrous carrying alk $B$ R2 type, another group carried other types of alk $B$ genes, and the third group lacked any alk $B$ genes.

\subsection{Degradation of Long Chain $c$-Alkane by Rhodococcus Species Carrying alkB R2 Type}

The degradation rates of long chain $c$-alkanes (UDC, DDC, and TDC) by 14 


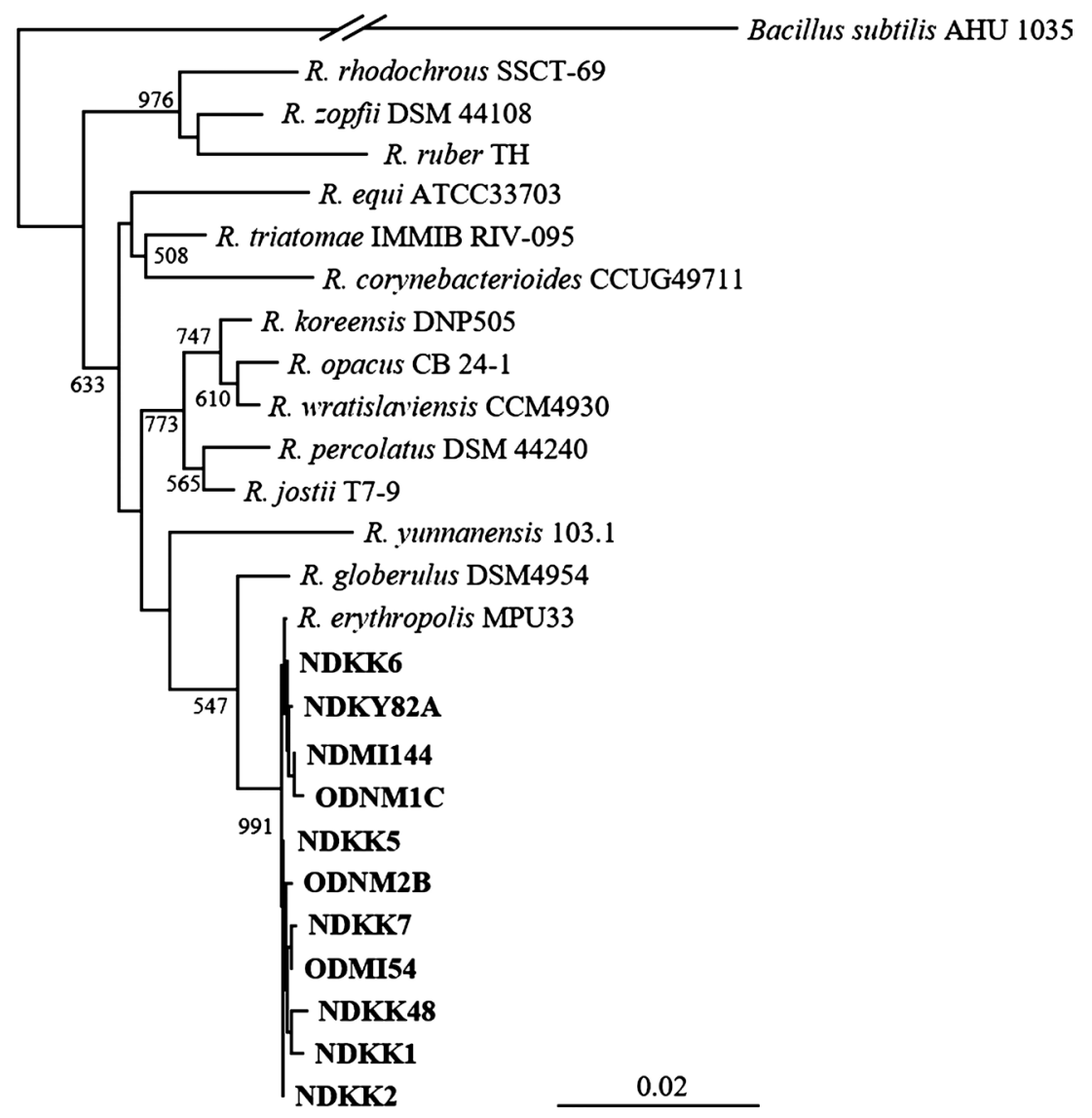

Figure 1. Phylogenetic tree based on 16S rRNA gene sequences of 26 strains of genus Rhodococcus. Sequences of the strain shown in bold were determined in this study and the other strains were taken from the GenBank database

(https://www.ncbi.nlm.nih.gov/genbank/). The tree was constructed by the neighbor-joining method. The scale bar indicates the number of substitutions per site. Bootstrap values (1000 replicates) greater than $50 \%$ are indicated in the corresponding nodes.

Table 1 . The presence of alkB genes and similarity to alk $B$ [alkB R2 type] genes.

\begin{tabular}{ccc}
\hline Strain & alkBGene & Similarity to alkB Gene [alkB R2 Type] (\%) \\
\hline R. erythropolis NDKK1 & + & 99.6 \\
R. erythropolis NDKK2 & + & 100 \\
R. erythropolis NDKK5 & + & 99.9 \\
R. erythropolis NDKK7 & + & 99.8 \\
R. erythropolis NDKK48 & + & 99.7 \\
R. erythropolis ODNM1C & + & 99.8 \\
R. erythropolis NDKY82A & + & 98.1 \\
R. erythropolis ODMI54 & + & 99.7 \\
R. erythropolis ODNM2B & + & 99.2 \\
R. erythropolis NDMI144 & + & 99.7 \\
R. erythropolis NBRC15567 & + & 95.7 \\
\hline
\end{tabular}

*alkB gene [alkB R2 type] from Rhodococcus erythropolis NDKK6 [1]. 
Table 2. The presence of alkB genes similarity to alkB genes [alkB R2 type], and types of alk $B$ gene.

\begin{tabular}{|c|c|c|c|}
\hline Strain & alkB Gene & $\begin{array}{l}\text { Similarity to alk } B \text { Gene } \\
\text { [alkB } 2 \text { 2 Type] }(\%)^{*}\end{array}$ & $\begin{array}{l}\text { Type of } \\
\text { alkB gene }\end{array}$ \\
\hline R. rhodochrous $\mathrm{NBRC} 15564$ & + & 100 & alkB R2 \\
\hline R. baikonurensis NBRC100611 & + & 99.7 & alkB R2 \\
\hline R. wratislaviensis $\mathrm{NBRC} 100605$ & + & 22.6 & alkB RW \\
\hline R. opacus NBRC100624 & + & 23.4 & alk $B$ ROP \\
\hline R. ruber NBRC15591 & + & 30.5 & alkB $\mathrm{RR}$ \\
\hline R. equi NBRC101255 & + & 78.3 & alkB $\mathrm{RE}$ \\
\hline R. percolatus $\mathrm{NBRC} 100626$ & + & 21.9 & alkB ROP \\
\hline R. jostii NBRC16295 & + & 30.1 & alkB RJ \\
\hline R. triatomae NBRC103116 & + & 30.1 & alkB R1 \\
\hline R. koreensis NBRC100607 & + & 30.5 & alkB RK \\
\hline R. corynebacterioides NBRC14404 & + & 24.1 & alkB RC \\
\hline R. zopfii NBRC100606 & + & 30.7 & alkB $\mathrm{RZ}$ \\
\hline R. tukisamuensis NBRC100609 & - & & \\
\hline R. maanshanensis $\mathrm{NBRC} 100610$ & - & & \\
\hline R. pyridinivorans $\mathrm{NBRC} 100608$ & - & & \\
\hline R. kroppenstedtii NBRC103113 & - & & \\
\hline R. rhodnii NBRC100604 & - & & \\
\hline R. coprophilus $\mathrm{NBRC} 100603$ & - & & \\
\hline
\end{tabular}

*alkB gene [alkB R2 type] from Rhodococcus erythropolis NDKK6 [1].

Rhodococcus strains carrying alkB R2 type are shown in Table 3. The average degradation rates of UDC, DDC, and TDC were 55.5\%, 31.8\%, and $55.2 \%$, respectively. Strain ODNM2B showed the highest degradation rate $(98.9 \%)$ of UDC. Similarly, strains NDKK2 and ODNM2B showed superior degradation of DDC and TDC (42.9\% and 94.6\%, respectively). Figure 3 shows the degradation of UDC by $R$. erythropolis NDKK6. These observations of $R$. erythropolis strains including our identified strains and one from NBRC indicate that alkB R2 type plays an important role in the degradation of long chain $c$-alkanes, and that Rhodococcus carrying alkB R2 type can utilize $n$-hexadecane [40].

\subsection{Degradation of Long Chain $c$-Alkane by Strains Carrying Non-alkB R2 Type}

The degradation rates of long chain $c$-alkanes (UDC, DDC, and TDC) by 10 Rhodococcus species carrying non-alkB R2 type are shown in Table 4. Average degradation rates of UDC, DDC, and TDC were $49.4 \%, 29.4 \%$, and $53.9 \%$, respectively. Although strains of the genus Rhodococcus carrying alkB genes can degrade hydrocarbons such as long chain $c$-alkanes, the degradation rates of strains carrying non-alkB R2 type were lower than those carrying alk $B$ R2 type 


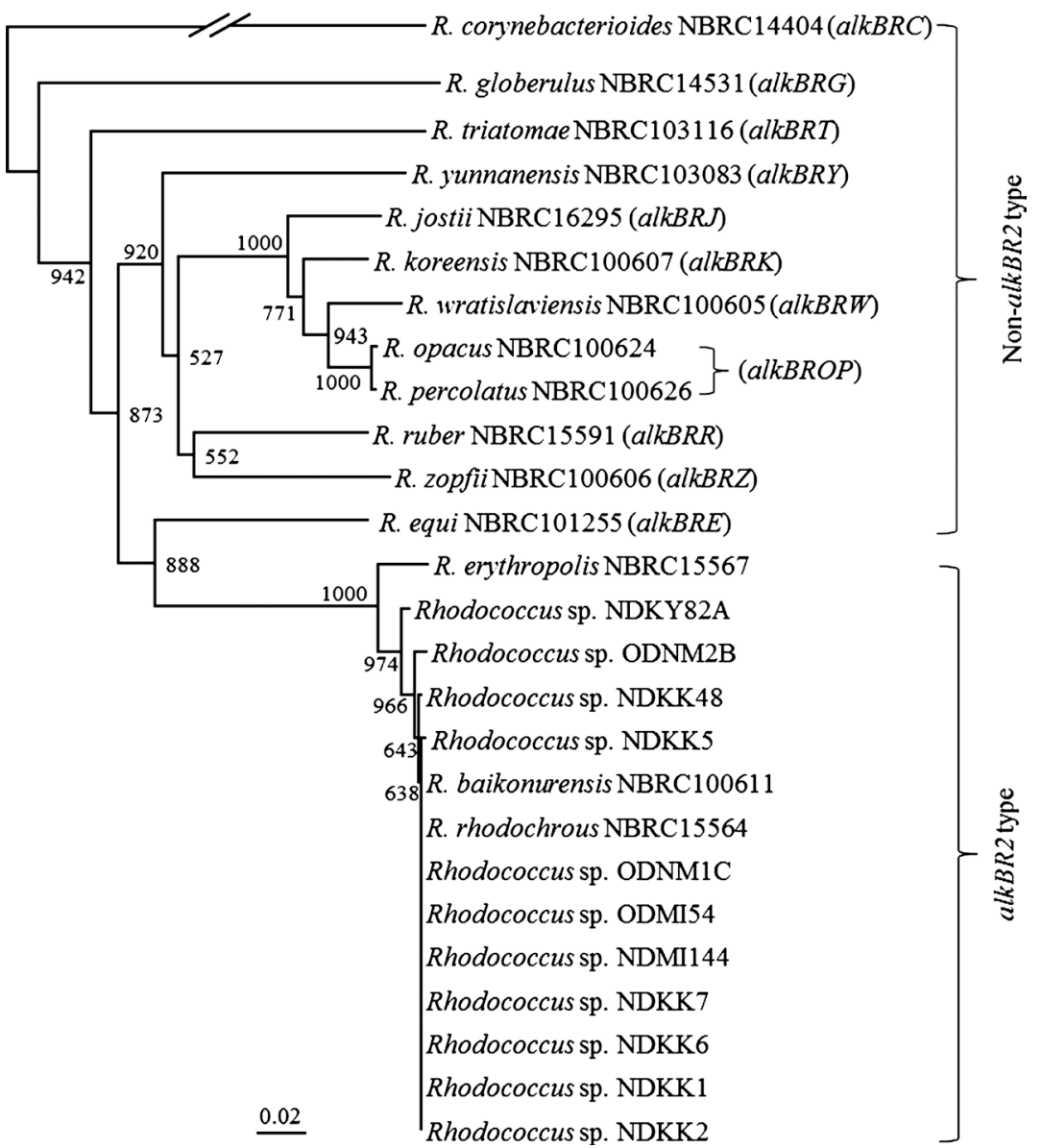

Figure 2. Phylogenetic tree based on alkane hydroxylase (alkB) gene sequences of 24 strains of the genus Rhodococcus. The scale bar indicates the number of substitutions per site. Corresponding gene names of each strain and group of strains are followed by names in parenthesis and braces, respectively. The tree was constructed by the neighbor-joining method. Bootstrap values (1,000 replicates) greater than $50 \%$ are indicated in the corresponding nodes.

(Table 3 and Table 4). This indicates that alkB R2 type was more suitable for the degradation of long chain $c$-alkanes. Moreover, the higher degradation rates of UDC and TDC compared with DDC suggest that long chain $c$-alkanes with an odd number of carbon atoms are easier to biodegrade by Rhodococcus species [21].

\subsection{Degradation of Long Chain $c$-Alkane by Strains Carrying No alkB Genes}

The degradation rates of long chain $c$-alkanes (UDC, DDC, and TDC) by 6 strains carrying no alkB genes are shown in Table 5. R. rhodnii NBRC100604 had the highest degradation rate of UDC, DDC, and TDC among all 6 strains. The average degradation rates of UDC, DDC, and TDC by these 6 strains were $19.3 \%, 13.3 \%$, and $19.1 \%$, respectively. The average degradation ratios of UDC, DDC, and TDC by strains carrying no alk $B$ genes were lower than in these by strains carrying alk $B$ [alk $B \mathrm{R} 2$ type] and alk $B$ [non-alk $B \mathrm{R} 2$ type]. Strains of genus 
Rhodococcus carrying alk $B$ genes had higher degradation abilities of long-chain $c$-alkane than those of strains carrying no alkB genes (Table 3 and Table 5). However, $R$. rhodnii NBRC100604 carrying no alkB gene showed a degradation rate of above $30 \%$. The ability of long-chain $c$-alkane degradation might be regulated

Table 3. The degradation of long-chain $c$-alkanes by stains harboring alkB [alkB $\mathrm{R} 2$ type] in the genus Rhodococcus.

\begin{tabular}{cccc}
\hline \multirow{2}{*}{ Strain } & \multicolumn{3}{c}{ Degradation Ratio (\%)* } \\
\cline { 2 - 4 } & $\begin{array}{c}\text { Undecylcyclohexane } \\
\text { (UDC) }\end{array}$ & $\begin{array}{c}\text { Dodecylcyclohexane } \\
\text { (DDC) }\end{array}$ & $\begin{array}{c}\text { Tridecylcyclohexane } \\
\text { (TDC) }\end{array}$ \\
\hline R. erythropolis NDKK1 & $16.0 \pm 7.5$ & $31.7 \pm 8.7$ & $17.9 \pm 7.3$ \\
R. erythropolis NDKK2 & $6.7 \pm 10.7$ & $42.9 \pm 10.2$ & $23.5 \pm 3.2$ \\
R. erythropolis NDKK5 & $66.7 \pm 0.2$ & $42.2 \pm 1.8$ & $40.6 \pm 10.0$ \\
R. erythropolis NDKK6 & $38.8 \pm 1.0$ & $18.9 \pm 6.2$ & $75.7 \pm 6.1$ \\
R. erythropolis NDKK7 & $53.5 \pm 3.6$ & $42.1 \pm 4.0$ & $46.7 \pm 9.1$ \\
R. erythropolis NDKK48 & $40.4 \pm 2.5$ & $33.1 \pm 12.6$ & $81.4 \pm 0.1$ \\
R. erythropolis ODNM1C & $78.2 \pm 2.4$ & $41.8 \pm 2.9$ & $91.0 \pm 1.1$ \\
R. erythropolis NDKY82A & $52.7 \pm 4.9$ & $39.1 \pm 9.2$ & $78.4 \pm 1.5$ \\
R. erythropolis ODMI54 & $68.2 \pm 5.0$ & $37.8 \pm 8.2$ & $46.8 \pm 2.6$ \\
R. erythropolis ODNM2B & $98.9 \pm 0.2$ & $30.3 \pm 3.5$ & $94.6 \pm 6.7$ \\
R. erythropolis NDMI144 & $91.4 \pm 3.9$ & $27.7 \pm 10.3$ & $39.9 \pm 8.3$ \\
R. erythropolis NBRC15567 & $64.5 \pm 9.4$ & $0.0 \pm 1.5$ & $75.4 \pm 1.5$ \\
R. erythropolis NBRC15564 & $50.6 \pm 3.9$ & $41.6 \pm 9.1$ & $39.6 \pm 7.1$ \\
R. baikonurensis & $50.4 \pm 3.8$ & $16.0 \pm 3.0$ & $20.6 \pm 5.7$ \\
NBRC100611 & 55.5 & 31.8 & 55.2 \\
\hline Average & & & \\
\hline
\end{tabular}

$*_{n}=3$.

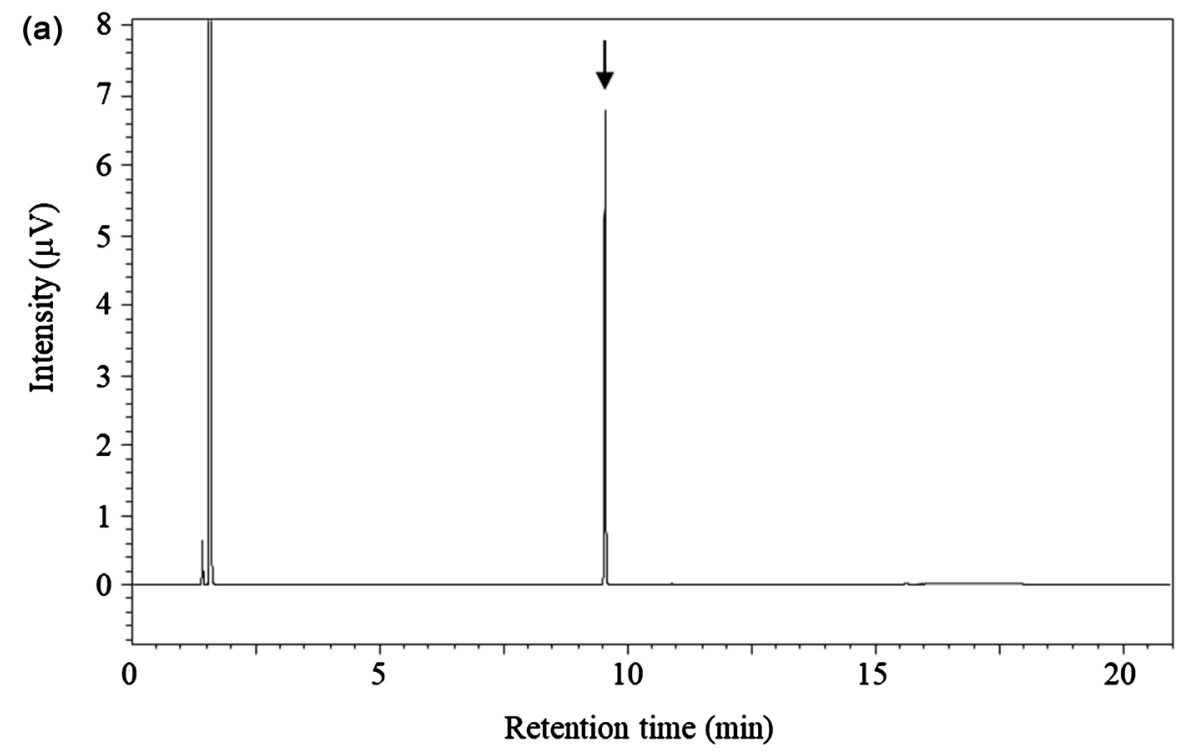




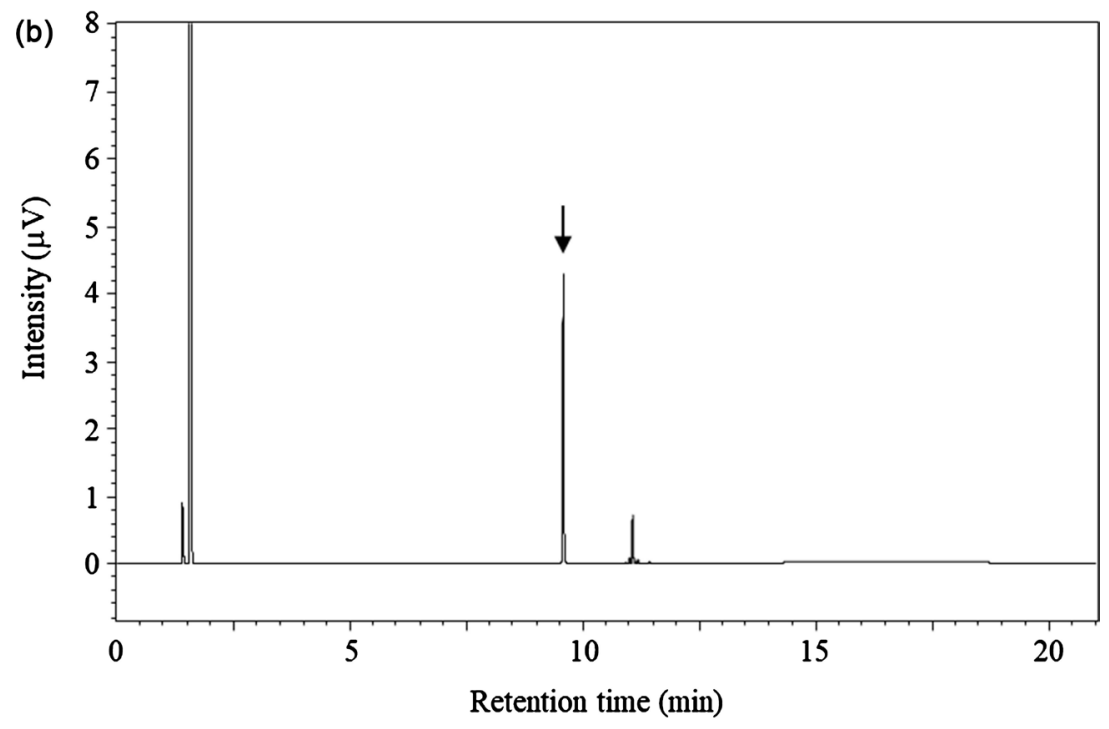

Figure 3. Gas chromatograms of UDC degraded by R. erythropolis NDKK6. Arrows indicate the peak of UDC. Images of gas chromatograms of LB medium with UDC substrate cultivated without (a) and with (b) R. erythropolis NDKK6.

Table 4. The degradation of long-chain $c$-alkanes by stains harboring alkB genes [non-alkB R2 type] in the genus Rhodococcus.

\begin{tabular}{|c|c|c|c|c|}
\hline \multirow{2}{*}{ Strain } & \multirow{2}{*}{ Type of alk $B$ Gene } & \multicolumn{3}{|c|}{ Degradation Ratio $(\%)^{\star}$} \\
\hline & & Undecylcyclohexane (UDC) & Dodecylcyclohexane (UDC) & Tridecylcyclo-hexane (UDC) \\
\hline R. wratislaviensis $\mathrm{NBRC} 100605$ & alkB RW & $39.7 \pm 5.2$ & $58.6 \pm 4.0$ & $25.1 \pm 2.1$ \\
\hline R. opacus NBRC100624 & alkB ROP & $94.9 \pm 1.4$ & $56.8 \pm 5.8$ & $43.1 \pm 0.4$ \\
\hline R. percoletus NBRC100626 & alk $B$ ROP & $47.1 \pm 13.5$ & $35.7 \pm 2.3$ & $60.6 \pm 11.1$ \\
\hline R. ruber $\mathrm{NBRC} 15591$ & alkB $\mathrm{RR}$ & $98.2 \pm 1.6$ & $55.9 \pm 3.6$ & $43.2 \pm 3.4$ \\
\hline R. equi NBRC101255 & alk $B \mathrm{RE}$ & $48.9 \pm 2.1$ & $39.3 \pm 3.4$ & $98.4 \pm 1.6$ \\
\hline R. jostii NBRC16295 & alkB RJ & $29.8 \pm 4.9$ & $27.8 \pm 10.7$ & $65.0 \pm 8.2$ \\
\hline R. triatomae NBRC103116 & alk $B$ R1 & $34.0 \pm 14.2$ & $15.9 \pm 7.4$ & $75.3 \pm 1.7$ \\
\hline R. koreensis NBRC100607 & alkB RK & $6.0 \pm 10.6$ & $4.2 \pm 5.4$ & $5.5 \pm 2.3$ \\
\hline R. corynebacterioides NBRC14404 & alkB RC & $41.4 \pm 6.5$ & $0.0 \pm 10.2$ & $62.3 \pm 0.6$ \\
\hline R. zopfii NBRC100606 & $\operatorname{alk} B \mathrm{RZ}$ & $53.9 \pm 9.1$ & $0.0 \pm 9.7$ & $60.3 \pm 5.3$ \\
\hline Average & & 49.4 & 29.4 & 53.9 \\
\hline
\end{tabular}

${ }^{*} \mathrm{n}=3$.

Table 5. The degradation of long-chain $c$-alkanes by stains harboring no alkB genes in the genus Rhodococcus.

\begin{tabular}{cccc}
\hline \multirow{2}{*}{ Strain } & \multicolumn{3}{c}{ Degradation Ratio (\%) } \\
\cline { 2 - 4 } & Undecylcyclohexane (UDC) & Dodecylcyclohexane (UDC) & Tridecylcyclo-hexane (UDC) \\
\hline R. tukisamuensis NBRC100609 & $26.0 \pm 1.4$ & $4.1 \pm 11.0$ & $20.1 \pm 8.0$ \\
R. maanshanensis NBRC100610 & $18.3 \pm 7.4$ & $13.4 \pm 4.2$ & $18.6 \pm 3.4$ \\
R. pyridinivorans NBRC100608 & $2.0 \pm 1.4$ & $11.2 \pm 13.1$ & $19.6 \pm 10.2$ \\
R. kroppenstedtii NBRC103113 & $12.3 \pm 5.2$ & $1.7 \pm 1.0$ & $15.9 \pm 4.2$ \\
R. rhodnii NBRC100604 & $34.7 \pm 11.5$ & $34.2 \pm 3.8$ & $34.8 \pm 3.3$ \\
R. coprophilus NBRC100603 & $22.2 \pm 3.3$ & $15.4 \pm 6.7$ & $5.6 \pm 7.1$ \\
Average & 19.3 & 13.3 & 19.1 \\
\hline
\end{tabular}

${ }^{*} \mathrm{n}=3$. 
by the alkane hydroxylase gene, while genus Rhodococcus spp. carrying no alkB genes may degrade long-chain $c$-alkanes by other degradation systems such as those involving the cytochrome gene [41].

\subsection{Alkane Hydroxylase Gene-Carrying Bacteria and Their Roles in Material Circulation in Nature}

$c$-alkane-degrading bacteria belonging to the genus Rhodococcus isolated from their natural habitats in our previous study were closely related to $R$. erythropolis and strains harboring alkB $\mathrm{R} 2$ type [33]. Although many $c$-alkane-degrading bacteria of the genus Rhodococcus are widely distributed, long-chain $c$-alkanes are limited in the natural environment. These bacteria may utilize hydrocarbons such as the wax of leaves and aromatic compounds, which include linear or cyclic hydrocarbon components. Thus, these bacteria harboring alkane hydroxylase genes might contribute to the material circulation of several kinds of hydrocarbon compounds in nature [42].

\section{Conclusion}

To characterize the long-chain cyclic alkane ( $c$-alkane) degradation of bacteria in Rhodococcus, 11 strains were isolated from nature using long-chain $c$-alkane as a substrate. These strains were identified as $R$. erythropolis, and all were shown to carry the alkB R2 type. It was also confirmed that the degradation ratios of long-chain $c$-alkanes by Rhodococcus carrying the alkB $\mathrm{R} 2$ type of gene (55.5\% of UDC, $31.8 \%$ of DDC, and $55.2 \%$ of TDC) were higher than in those carrying the non-alkB R2 type of gene (49.4\% of UDC, $29.4 \%$ of DDC, and $53.9 \%$ of TDC) and no alkB gene (19.3\% of UDC, $13.3 \%$ of DDC, and $19.1 \%$ of TDC).

\section{Conflicts of Interest}

The authors declare no conflicts of interest regarding the publication of this paper.

\section{References}

[1] Usman, M., Faure, P., Hanna, K., Abdelmoula, M. and Ruby, C. (2012) Application of Magnetite Catalyzed Chemical Oxidation (Fenton-Like and Persulfate) for the Remediation of Oil Hydrocarbon Contamination. Fuel, 96, 270-276. https://doi.org/10.1016/j.fuel.2012.01.017

[2] Hatayama, K., Sakihama, Y., Matsumiya, Y. and Kubo, M. (2008) Construction of an Efficient Bioremediation System for Petroleum Hydrocarbon-Contaminated Soils Using Specific Hydrocarbon-Degrading Bacteria and Bacterial Biomass Monitoring. In: Domínguez, J.B., Ed., Soil Contamination Research Trends, Nova Science Publishers, NY, 143-160.

[3] Dua, M., Johri, A.K., Singh, A. and Sethunathan, N. (2002) Biotechnology and Bioremediation: Successes and Limitations. Applied Microbiology and Biotechnology, 59, 143-152. https://doi.org/10.1007/s00253-002-1024-6

[4] Vidali, M. (2001) Bioremediation. An Overview. Pure and Applied Chemistry, 73, 1163-1172. https://doi.org/10.1351/pac200173071163 
[5] Stroud, J.L., Paton, G.I. and Semple, K.T. (2007) Microbe-Aliphatic Hydrocarbon Interactions in Soil: Implications for Biodegradation and Bioremediation. Journal of Applied Microbiology, 102, 1239-1253. https://doi.org/10.1111/j.1365-2672.2007.03401.x

[6] Kissin, Y.V. (1990) Catagenesis of Light Cycloalkanes in Petroleum. Organic Geochemistry, 15, 575-594. https://doi.org/10.1016/0146-6380(90)90103-7

[7] Korda, A., Santas, P., Tenente, A. and Santas, R. (1997) Petroleum Hydrocarbon Bioremediation: Sampling Analytical Techniques, in Situ Treatment and Commercial Microorganisms Currently Used. Applied Microbiology and Biotechnology, 48, 677-686. https://doi.org/10.1007/s002530051115

[8] Pritchard, P.H., Mueller, J.G., Rogers, J.C., Kremer, F.V. and Glaser, J.A. (1992) Oil Spill Bioremediation: Experiences, Lessons and Results from the Exxon Valdez Oil Spill in Alaska. Biodegradation, 3, 315-335. https://doi.org/10.1007/BF00129091

[9] Adhikari, D., Perwira, I.Y., Araki, K.S. and Kubo, M. (2016) Sitimulation of Soil Microorganisms in Pesticide-Contaminated Soil Using Organic Materials. AIMS Bioengineering, 3, 379-388. https://doi.org/10.3934/bioeng.2016.3.379

[10] Blakley, E.R. (1978) The Microbial Degradation of Cyclohexanecarboxylic Acid by a $\beta$-Oxidation Pathway with Simultaneous Induction to the Utilization of Benzoate. Canadian Journal of Microbiology, 24, 847-855. https://doi.org/10.1139/m78-141

[11] Blakley, E.R. and Papish, B. (1982) The Metabolism of Cyclohexanecarboxylic Acid and 3-Cyclohexenecarboxylic Acid by Pseudomonas putida. Canadian Journal of Microbiology, 28, 1324-1329. https://doi.org/10.1139/m82-198

[12] Komukai-Nakamura, S., Sugiura, K., Yamauchi-Inomata, Y., Toki, H., Venkateswaran, K., Yamamoto, S., Tanaka, H. and Harayama, S. (1996) Construction of Bacterial Consortia That Degrade Arabian Light Crude Oil. Journal of Fermentation and Bioengineering, 82, 570-574. https://doi.org/10.1016/S0922-338X(97)81254-8

[13] Aislabie, J., Saul, D.J. and Foght, J.M. (2006) Bioremediation of Hydrocarbon-Contaminated Polar Soils. Extremophiles, 10, 171-179. https://doi.org/10.1007/s00792-005-0498-4

[14] Zampolli, J., Collina, E., Lasagni, M. and Gennaro1, P.G. (2014) Biodegradation of Variable-Chain-Length $n$-alkanes in Rhodococcus opacus $\mathrm{R} 7$ and the Involvement of an Alkane Hydroxylase System in the Metabolism. AMB Express, 4, 73. https://doi.org/10.1186/s13568-014-0073-4

[15] Perry, J.J. (1979) Microbial Cooxidations Involving Hydrocarbons. Microbiological Reviews, 43, 59-72.

[16] Throne-Holst, M., Wentzel, A., Ellingsen, T.E., Kotlar, H.K. and Zotchev, S.B. (2007) Identification of Novel Genes Involved in Long-Chain n-Alkane Degradation by Acinetobacter sp. Strain DSM 17874. Applied and Environmental Microbiology, 73, 3327-3332. https://doi.org/10.1128/AEM.00064-07

[17] Lal, B. and Khanna, S. (1996) Degradation of Crude Oil by Acinetobacter calcoaceticus and Alcaligenes odorans. Journal of Applied Microbiology, 81, 355-362. https://doi.org/10.1111/j.1365-2672.1996.tb01926.x

[18] Sakai, Y., Maeng, J.H., Tani, Y. and Kato, N. (1994) Use of Long-Chain n-alkanes (C13-C44) by an Isolate, Acinetobacter sp. M-1. Bioscience, Biotechnology and Biochemistry, 58, 2128-2130. https://doi.org/10.1271/bbb.58.2128

[19] Táncsics, A., Benedek, T., Szoboszlay, S., Veres, P.G., Farkas, M., Máthé, I., Márialigeti, K., Kukolya, J., Lányi, S. and Kriszt, B. (2015) The Detection and Phylogenetic Analysis of the Alkane 1-Monooxygenase Gene of Members of the Genus Rhodococcus. Systematic and Applied Microbiology, 38, 1-7. 
https://doi.org/10.1016/j.syapm.2014.10.010

[20] Kubota, K., Koma, D., Matsumiya, Y., Chung, S.Y. and Kubo, M. (2008) Phylogenetic Analysis of Long-Chain Hydrocarbon-Degrading Bacteria and Evaluation of Their Hydrocarbon-Degradation by the 2,6-DCPIP Assay. Biodegradation, 19, 749-757. https://doi.org/10.1007/s10532-008-9179-1

[21] Koma, D., Sakashita, Y., Kubota, K., Fujii, Y., Hasumi, F., Chung, S.Y. and Kubo, M. (2004) Degradation Pathways of Cyclic Alkanes in Rhodococcus sp. NDKK48. Applied Microbiology and Biotechnology, 66, 92-99. https://doi.org/10.1007/s00253-004-1623-5

[22] Kostichka, K., Thomas, S.M., Gibson, K.J., Nagarajan, V. and Cheng, Q. (2001) Cloning and Characterization of a Gene Cluster for Cyclododecanone Oxidation in Rhodococcus ruber SC1. Journal of Bacteriology, 183, 6478-6486. https://doi.org/10.1128/JB.183.21.6478-6486.2001

[23] van Hamme, J.D., Odumeru, J.A. and Ward, O.P. (2000) Community Dynamics of a Mixed-Bacterial Culture Growing on Petroleum Hydrocarbons in Batch Culture. Canadian Journal of Microbiology, 46, 441-450. https://doi.org/10.1139/w00-013

[24] van Beilen, J.B., Smits, T.H.M., Roos, F.F., Brunner, T., Balada, S.B., Rothlisberger, M. and Witholt, B. (2005) Identification of an Aminno Acid Position That Determines the Substrate Range of Integral Membrane Alkane Hydroxylases. Journal of Bacteriology, 187, 85-91. https://doi.org/10.1128/JB.187.1.85-91.2005

[25] van Beilen, J.B. and Funhoff, E.G. (2007) Alkane Hydroxylases Involved in Microbial Alkane Degradation. Applied Microbiology and Biotechnology, 74, 13-21. https://doi.org/10.1007/s00253-006-0748-0

[26] Whyte, L.G., Smits, T.H.M., Labbé, D., Witholt, B., Greer, C.W. and van Beilen, J.B. (2002) Gene Cloning and Characterization of Multiple Alkane Hydroxylase Systems in Rhodococcus Strains Q15 and NRRL B-16531. Applied and Environmental Microbiology, 68, 5933-5942. https://doi.org/10.1128/AEM.68.12.5933-5942.2002

[27] Fujii, T., Narikawa, T., Takeda, K. and Kato, J. (2004) Biotransformation of Various Alkanes Using the Escherichia coli Expressing an Alkane Hydroxylase System from Gordonia sp. TF6. Bioscience, Biotechnology and Biochemistry, 68, 2171-2177. https://doi.org/10.1271/bbb.68.2171

[28] Vomberg, A. and Klinner, U. (2000) Distribution of alkB Genes within n-Alkane-Degrading Bacteria. Journal of Applied Microbiology, 89, 339-348. https://doi.org/10.1046/j.1365-2672.2000.01121.x

[29] Whyte, L.G., Hawari, J., Zhou, E., Bourbonniére, L., Inniss, W. and Greer, C.W. (1998) Biodegradation of Variable-Chain-Length Alkanes at Low Temperatures by a Psychrotrophic Rhodococcus sp. Applied and Environmental Microbiology, 64, 2578-2584.

[30] van Beilen, J.B., Smits, T.H.M., Whyte, L.G., Schorcht, S., Röthlisberger, M., Plaggemeier, T., Engesser, H. and Witholt, B. (2002) Alkane Hydroxylase Homologues in Gram-Positive Strains. Environmental Microbiology, 4, 676-682. https://doi.org/10.1046/j.1462-2920.2002.00355.x

[31] Hara, A., Baik, S.H., Syutsubo, K., Misawa, N., Smits, T.H.M., van Beilen, J.B. and Harayama, S. (2004) Cloning and Functional Analysis of alkB Genes in Alcanivorax borkumensis SK2. Environmental Microbiology, 6, 191-197. https://doi.org/10.1046/j.1462-2920.2003.00550.x

[32] Rehm, H.J. and Reiff, I. (1981) Mechanisms and Occurrence of Microbial Oxidation of Long-Chain Alkanes. In: Fiechter, A., Ed., Reactors and Reactions, Vol. 19: Advances in Biochemical Engineering, Springer, Berlin, 175-215. 
https://doi.org/10.1007/3-540-10464-X_18

[33] Fukuhara, Y., Horii, S., Matsuno, T., Matsumiya, Y., Mukai, M. and Kubo, M. (2013) Distribution of Hydrocarbon-Degrading Bacteria in the Soil Environment and Their Contribution to Bioremediation. Applied Biochemistry and Biotechnology, 170, 329-339. https://doi.org/10.1007/s12010-013-0170-x

[34] Perry, J.J. (1984) Microbial Metabolism of Cyclic Alkanes. In: Atlas, R.M., Ed., Petroleum Microbiology, Macmillan, 61-98.

[35] Koma, D., Sakashita, Y., Kubota, K., Fujii, Y., Hasumi, F., Chung, S.Y. and Kubo, M. (2003) Degradation of Car Engine Base Oil by Rhodococcus sp. NDKK48 and Gordonia sp. NDKY76A. Bioscience, Biotechnology and Biochemistry, 67, 1590-1593. https://doi.org/10.1271/bbb.67.1590

[36] Koma, D., Hasumi, F., Yamamoto, E., Ohta, T., Chung, S.Y. and Kubo, M. (2001) Biodegradation of Long-Chain $n$-Paraffins from Waste Oil of Car Engine by Acinetobacter sp. Journal of Bioscience and Bioengineering, 91, 94-96. https://doi.org/10.1016/S1389-1723(01)80120-1

[37] Koma, D., Hasumi, F., Chung, S.Y. and Kubo, M. (2003) Biodegradation of n-Alkylcyclohexanes by Co-Oxidation via Multiple Pathways in Acinetobacter sp. ODDK71. Journal of Bioscience and Bioengineering, 95, 641-644. https://doi.org/10.1016/S1389-1723(03)80178-0

[38] Iwamoto, T. and Nasu, M. (2001) Current Bioremediation Practice and Perspective. Journal of Bioscience and Bioengineering, 92, 1-8. https://doi.org/10.1016/S1389-1723(01)80190-0

[39] Sanpa, S., Sumiyoshi, S., Kujira, T., Matsumiya, Y. and Kubo, M. (2006) Isolation and Characterization of a Bluegill Degrading Microorganism, and Analysis of the Root Hair-Promoting Effect of the Degraded Products. Bioscience, Biotechnology and Biochemistry, 70, 340-347. https://doi.org/10.1271/bbb.70.340

[40] van Beilen, J.B., Li, Z., Duetz, W.A. and Witholt, B. (2003) Diversity of Alkane Hydroxylase Systems in the Environment. Oil Gas Science and Technology, 58, 427-440. https://doi.org/10.2516/ogst:2003026

[41] van Beilen, J.B., Funhoff, E.G., van Loon, A., Just, A., Kaysser, L., Bouza, M., Holtackers, R., Röthlisberger, M., Li, Z. and Witholt, B. (2006) Cytochrome P450 Alkane Hydroxylases of the CYP153 Family Are Common in Alkane-Degrading Eubacteria Lacking Integral Membrane Alkane Hydroxylases. Applied and Environmental Microbiology, 72, 59-65. https://doi.org/10.1128/AEM.72.1.59-65.2006

[42] Nie, Y., Chi, C.Q., Fang, H., Liang, J.L., Lu, S.L., Lai, G.L., Tang, Y.Q. and Wu, X.L. (2014) Diverse Alkane Hydroxylase Genes in Microorganisms and Environments. Scientific Reports, 4, Article No. 4968. https://doi.org/10.1038/srep04968 